\title{
Awareness of Antiretroviral Drug Therapy in Management of HIV Among Dental Students
}

\author{
Nurul Afiqah Amani Binti Zaaba1, Dhanraj Ganapathy² and Revathi Duraisamy \\ ${ }^{1}$ Saveetha Dental College and Hospitals, Saveetha Institute of Medical \\ and Technical Sciences, Saveetha University, Chennai, India \\ ${ }^{2}$ Professor and Head, Department of Prosthodontics, Saveetha Dental College and Hospitals, \\ Saveetha Institute of Medical and Technical Sciences, Saveetha University, Chennai, India \\ ${ }^{3}$ Senior Lecturer, Department of Prosthodontics, Saveetha Dental College and Hospitals, \\ Saveetha Institute of Medical and Technical Sciences,Saveetha University,Chennai, India
}

\section{ABSTRACT}

The aim of this study was to evaluate the awareness and knowledge of dental students toward the use of antiretroviral drug therapy in management of HIV. HIV is a chronic disease that can be managed by dental practitioners. It can be treated with antiretroviral drugs, which help to control progression into AIDS and reduce the mortality rates. A questionnaire was developed and the survey was conducted online via survey planet with 120 respondents. Data was then collected and analysed with IBM SPSS version 23. In this present study, 6.67\% postgraduates and 3.33\% interns have excellent knowledge on antiretroviral therapy. Majority of the respondents believed in the importance of knowledge on antiretroviral therapy (97.50\%). 63.33\% of the respondents stated that they have knowledge on triple combination drugs. $83.33 \%$ of the respondents were aware of the adverse effects of antiretroviral therapy. Association between response of the participants and knowledge on antiretroviral drugs was found to be statistically significant $(p<0.05)$. Within the limits of study, the majority of students showed an acceptable level of knowledge and awareness on antiretroviral drugs in management of HIV patients. Association between response of the participants and knowledge on antiretroviral drugs was found to be statistically significant. However, there was a lack of knowledge on the dosage and prescription of the antiretroviral drugs.

KEY WORDS: ANTIRETROVIRAL DRUGS; AWARENESS; DENTISTS; DRUG THERAPY; HIV; KNOWLEDGE.

\section{INTRODUCTION}

Nowadays, human immunodeficiency virus (HIV) can be managed as a chronic disease, by both medical and dental practitioners (Website, no date). Although it cannot be

\section{ARTICLE INFORMATION}

*Corresponding Author: dhanraj@saveetha.com

Received 10th June 2020 Accepted after revision 10th August 2020 Print ISSN: 0974-6455 Online ISSN: 2321-4007 CODEN: BBRCBA

Thomson Reuters ISI Web of Science Clarivate Analytics USA and Crossref Indexed Journal

\section{Clarivate crossef}

NAAS Journal Score 2020 (4.31) SJIF: 2020 (7.728)

A Society of Science and Nature Publication,

Bhopal India 2020. All rights reserved.

Online Contents Available at: http//www.bbrc.in/

Doi: http://dx.doi.org/10.21786/bbrc/13.7/51 cured, the progressions of the disease can be controlled with medical treatment. In general, HIV belongs to the retrovirus family that targets the cells in the human immune system to cause the infections. It usually will infect the CD4 cells. As the infections progressed, the number of CD4 cells in the host body will be decreased and causing decelerations of the cellular immune reaction against the infected cell (Levy, 2007; Blood', German Advisory Committee Blood (Arbeitskreis Blut) and Subgroup 'Assessment of Pathogens Transmissible by Blood', 2016). This will lead to poor functioning of the immune system in the host body causing direct or indirect cell infections. If this opportunistic infection

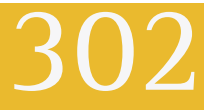


remains untreated, it will eventually lead to acquired immunodeficiency syndrome (AIDS), which is the last state of HIV infection (Keser, Göcüncü and Pekiner, 2019).

Basically, the first signs of HIV infection could be seen in the oral cavity. Several oral conditions can be used as indicators including hairy leukoplakia, oral candidiasis, necrotizing ulcerative periodontitis, oral ulcers, parotid swelling, linear gingival erythema, and Kaposi's sarcoma (Bonito et al., 2001). Presence of these oral conditions can be used for the detection and determining the progression of HIV into AIDS. These oral conditions can be used as the diagnostic criteria in about 60\%-70\% of HIV-positive patients (Keser, Göcüncü and Pekiner, 2019). On top of that, there is also invested in the prevalence of decay in HIV patients. Thus, most of the HIV infected patients will seek dental treatment (Magalhães, Oliveira and Prado, 2015). Therefore, dentists should have comprehensive knowledge on HIV and AIDS, in order to identify and manage HIV/AIDS patients when they report to dental clinics. This will help to prevent spreading of infections to the dentists as well as to other patients.

Next, the course of HIV infection is always chronic. Although it cannot be completely cured, with effective treatment and care, the HIV can be controlled. In general, HIV can be treated with antiretroviral drugs. These drugs will help to suppress the disintegration of CD4 cells as well as the clinical symptoms (Broder, 2010). Introduction of highly active antiretroviral treatment (HAART) in most of the countries, showed major reduction on the incidence of AIDS as well as reduction in the mortality rates in association of the disease (Campo et al., 2007). There are major differences in patients treated with antiretroviral therapy with untreated patients. In untreated HIV-1 patients, AIDS usually appears after 10 years, while for HIV-2 patients, HIV usually will progress after 15 years. However, when they are treated with antiretroviral therapy, it would help to prolong the duration of HIV infection before it reaches the last stage of AIDS, with or without severe symptoms (Jaffar et al., 2004; Blood', German Advisory Committee Blood (Arbeitskreis Blut) and Subgroup 'Assessment of Pathogens Transmissible by Blood', 2016).

Based on the previous literature by Grover et al, the majority of dental students have good knowledge about HIV infections (Grover et al., 2014). This shows that most dental students are educated with good knowledge on standard precautions for management of infection of blood borne pathogens (Oberoi, Marya, et al., 2014), especially of HIV. In a study reported by Oberoi et al, most of the dental practitioners have a thorough knowledge regarding $\mathrm{HIV}$ and the drugs to be taken under the antiretroviral therapy (Oberoi, Sharma, et al., 2014). Therefore, it is important to have both theoretical and practical knowledge on HIV infections. It can be applied during dental practices and precautions can be taken to handle patients with this opportunistic infection. This will help dentists to identify and provide early diagnosis of HIV and treat it with antiretroviral therapy in order to halt the progressions into AIDS.

Previously our department has published extensive research on various aspects of prosthetic dentistry ('Evaluation of Corrosive Behavior of Four Nickelchromium Alloys in Artificial Saliva by Cyclic Polarization Test:An in vitro Study', 2017; Ganapathy, Kannan and Venugopalan, 2017; Jain, 2017a, 2017b; Ranganathan, Ganapathy and Jain, 2017; Ariga et al., 2018; Gupta, Ariga and Deogade, 2018; Anbu et al., 2019; Ashok and Ganapathy, 2019; Duraisamy et al., 2019; Varghese, Ramesh and Veeraiyan, 2019), this vast research experience has inspired us to research about the awareness and knowledge of dental students toward the use of antiretroviral drug therapy in management of HIV.

\section{MATERIAL AND METHODS}

This retrospective study was designed to assess the awareness and knowledge of dentists toward the use of antiretroviral drug therapy in management of HIV. A pretest of validated questionnaires was drafted and emphasising on the knowledge of dental students on the use of antiretroviral drug therapy and its adverse effects. The pretested questionnaire consists of two parts. The first part was based upon the demographic data, such as age, gender and level of education. The second part was about the knowledge and awareness along with adverse effects of antiretroviral drugs if presented. The questionnaire was designed in a closed ended question which consists of 12 questions. The survey was conducted online via survey planet from November 2019 till January 2020. The inclusion criteria for this study were undergraduate and postgraduate students aged above 18 years old and have experience training in dental clinics for at least one year. Any students with no experience in clinical practice, age below 18 years old were excluded from the study.

About 120 anonymous undergraduates (including third years, final years and interns) and postgraduates of Saveetha Dental College and Hospitals, Chennai, India completed the online survey under university settings. The survey was conducted online via survey planet and the responses of the students were recorded. Data was then collected via survey planet. Then, the collected data was recorded in MS excel sheet and tabulated. IBM SPSS version 23 was used for importing data. The descriptive and inferential statistics was done for analysis. The Statistical test of Pearson's Chi square test was done. Then, variables definition processes were done by using table and graphical illustrations.

\section{RESULTS AND DISCUSSION}

A total of 120 undergraduates and postgraduates were recruited for the present study, where 73 (60.8\%) were female and 47 (39.2\%) were male. The patients had an age range of 17 - 35 years with mean age of 24.5. Out of 120 students, 20 were third years (16.7\%), 24 were 
final years (20\%), 60 were interns (50\%) and 16 were postgraduates (13.3\%). [Figure 1].

Figure 1: Pie chart depicting the frequency distribution of undergraduates and postgraduates students based on their year of study. 50\% of the respondents were interns (yellow), 20\% of the respondents were final year students (green), $16.67 \%$ of the respondents were third year undergraduate students (blue) and 13.33\% of the respondents were postgraduate students (purple).

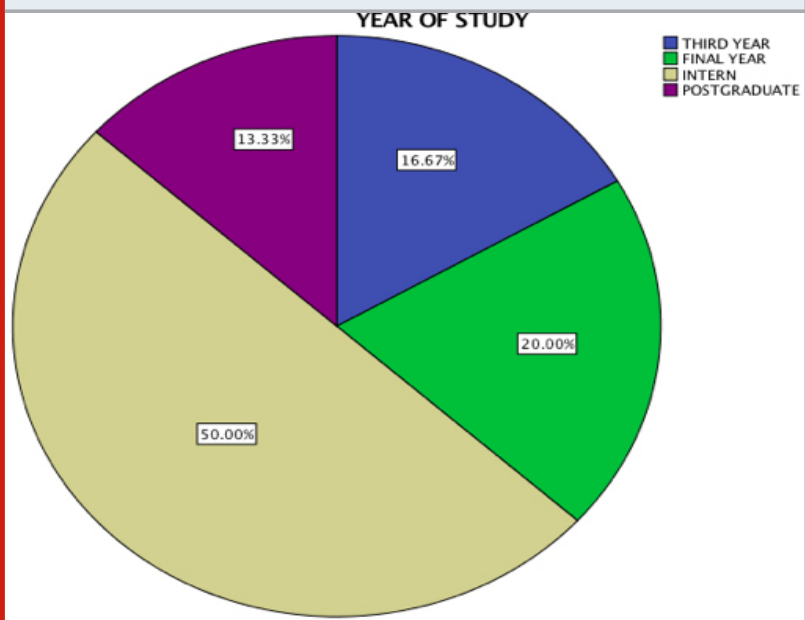

Figure 2: Bar chart depicting associations of the year of study and knowledge of respondents on the antiretroviral therapy. $\mathrm{X}$ axis represents the years of study and the $\mathrm{Y}$ axis represents the number of participants with their responses based on their knowledge on antiretroviral therapy. 6.67\% postgraduates have excellent knowledge (blue) and good knowledge (green). 3.33\% interns have excellent knowledge (blue). 14.17\% of both final years and third years have moderate knowledge on antiretroviral therapy (yellow). Association between year of study and knowledge of respondents on the antiretroviral therapy was found to be statistically significant (Pearson Chi square value- 49.537; $\mathrm{p}=0.000)(\mathrm{p}<0.05)$. Hence Statistically significant.

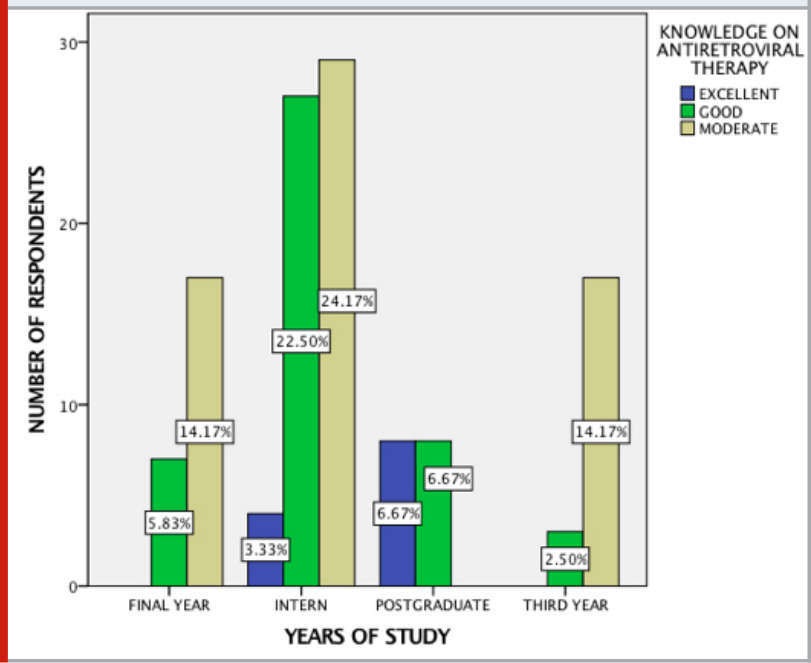

The knowledge of students on the antiretroviral therapy was assessed. Among 20 third year students, good knowledge was observed among 3 students (2.5\%) and moderate knowledge was observed among 17 students (14.17\%). Among 24 final year students, good knowledge was observed among 7 students (5.83\%) and moderate knowledge was observed among 17 students (14.17\%). Among 60 interns, excellent knowledge was observed among 4 students (3.33\%), good knowledge was observed among 27 students (22.5\%) and moderate knowledge was observed among 29 students (24.17\%). Among 8 postgraduates, excellent knowledge was observed among 8 students (6.67\%) and good knowledge was observed among 8 students (6.67\%). The association between year of study and knowledge of respondents on the antiretroviral therapy was found to be statistically significant (Pearson Chi square value- 49.537; $p=0.000$ ). [Figure 2].

Based upon the importance of knowledge of antiretroviral therapy in managing HIV patients among dentists. 117 of the respondents believed in the importance of knowledge on antiretroviral therapy $(97.5 \%)$.

Figure 3: Pie chart showing the importance of knowledge of antiretroviral therapy among dentists. $97.50 \%$ of the respondents believed in the importance of knowledge on antiretroviral therapy (blue).

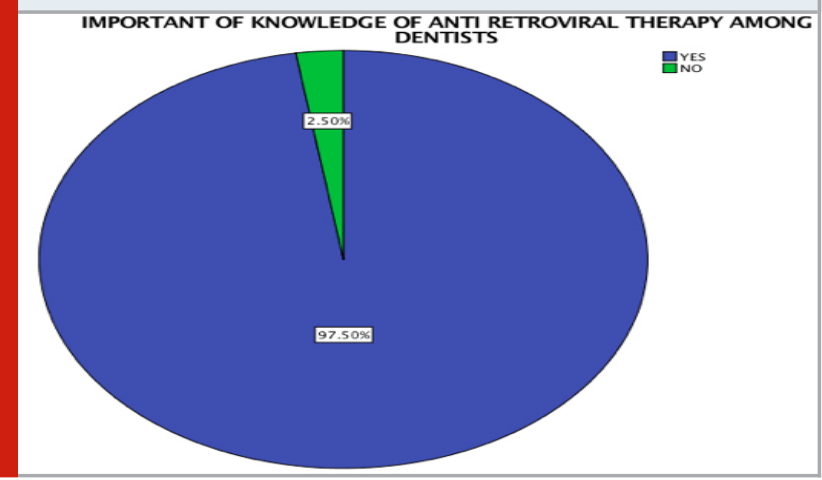

Figure 4: Pie chart showing the knowledge of respondents on 'when to prescribe of administered antiretroviral drugs'. $65.83 \%$ of respondents stated that they have knowledge of prescribing antiretroviral drugs (blue).

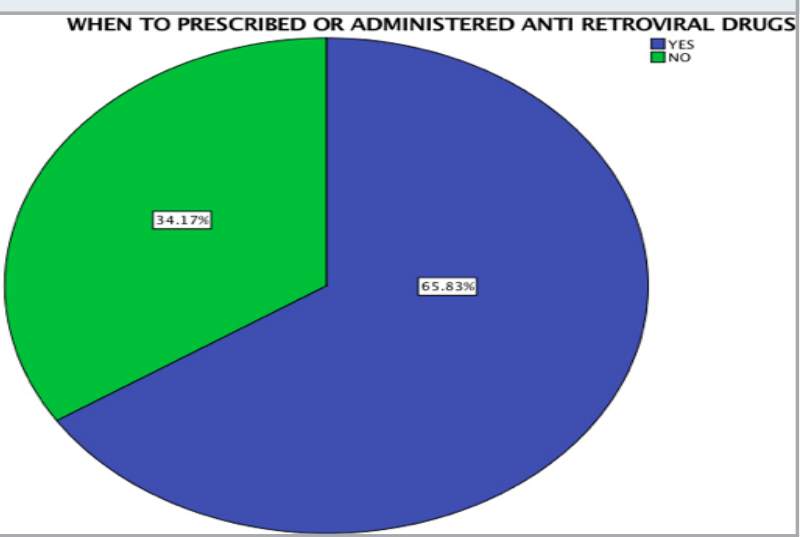


Figure 5: Pie chart showing the experience of respondents in prescribing antiretroviral drugs to HIV patients. Only, $6.67 \%$ of the respondents previously prescribed antiretroviral drugs to their patients. 93.33\% does not have any experience in prescribing antiretroviral drugs (green).

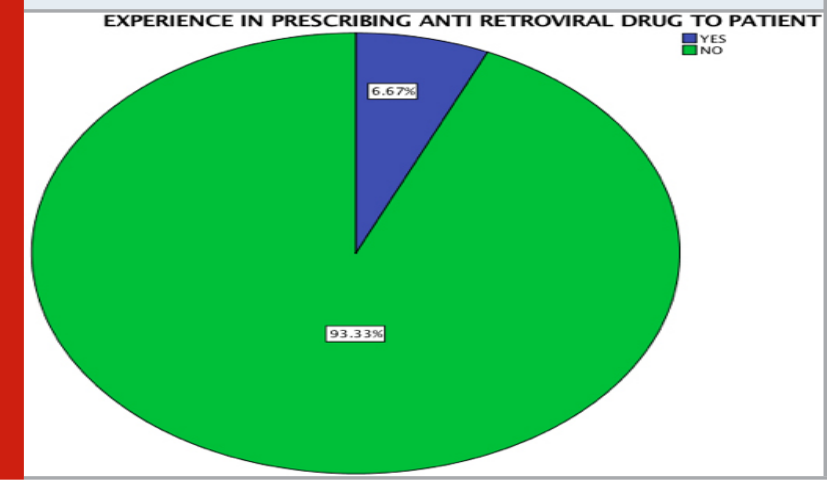

Figure 6: Pie chart showing the knowledge on the exact dosage of antiretroviral drugs. Only 5.83\% of the respondents stated that they knew the exact dosage of antiretroviral drugs (blue).

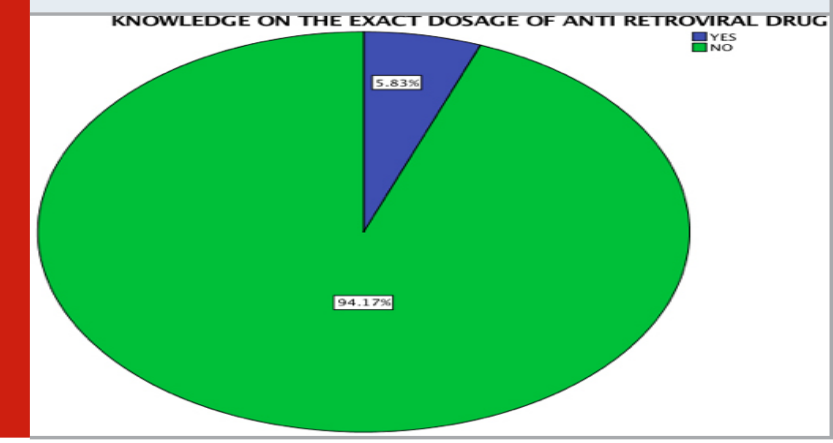

Figure 7: Pie chart showing the knowledge on the triple combination drug of antiretroviral therapy in HIV. 63.33\% of the respondents stated that they have knowledge on triple combination drugs (blue). $36.67 \%$ of the respondents stated that they did not have knowledge on triple combination drugs (green).

\section{TRIPLE COMBINATION DRUG OF ANTI RETROVIRAL THERAPY IN HIV}

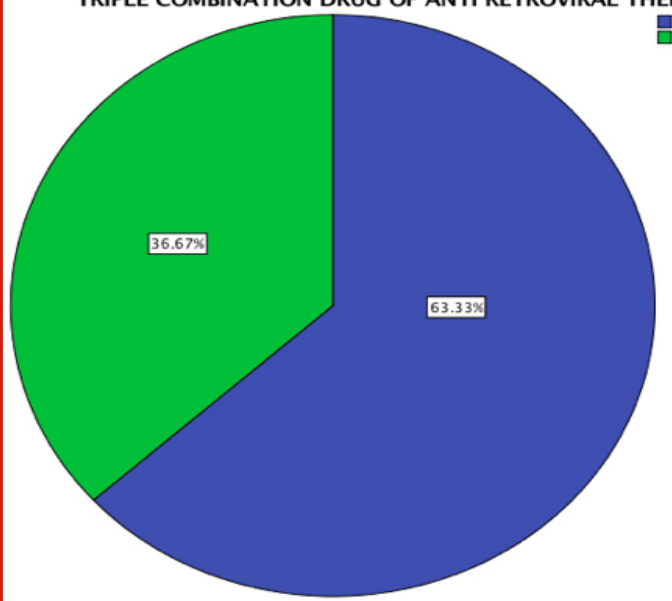

Whereas, only 3 students stated that theoretical knowledge on antiretroviral therapy was not important (2.5\%). [Figure 3]. When enquiring about the knowledge of respondents on administration of antiretroviral drugs, 79 students stated that they have knowledge of prescribing antiretroviral drugs (65.83\%). While 41 students stated that they did not have knowledge on prescribing antiretroviral drugs (34.17\%). [Figure 4].

Figure 8: Pie chart showing knowledge on the failure of antiretroviral therapy due to drug resistance . 83.33\% of the respondents stated that they believe drug resistance can cause failure of treatment (blue). 16.67\% of the respondents stated that drug resistance did not cause failure of treatment (green).

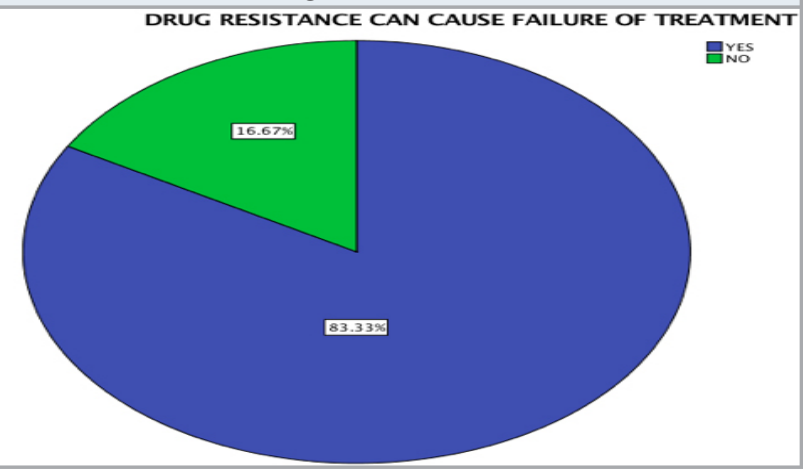

Figure 9: Pie chart showing importance of drug resistance testing. $70.83 \%$ of the respondents believe in the importance of drug resistance testing. $29.17 \%$ of the respondents stated that drug resistance testing was not important.

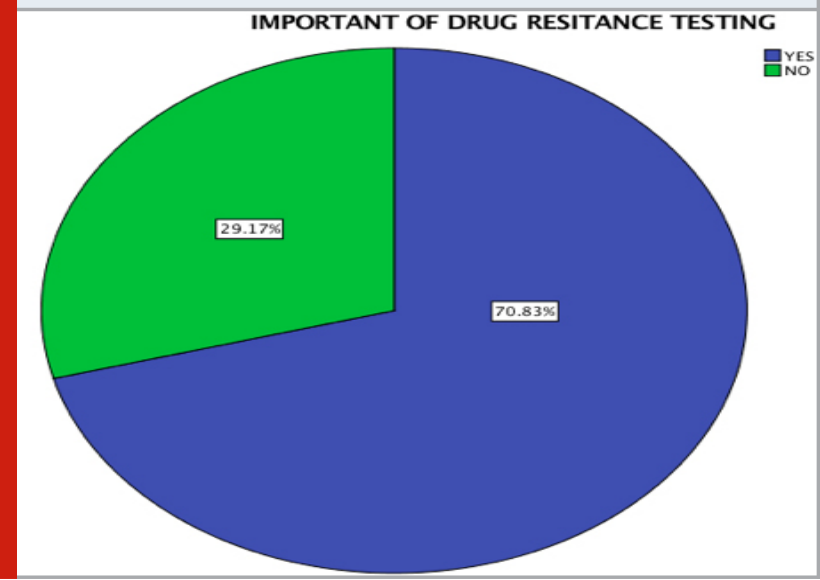

Assessment of experience of respondents in prescribing antiretroviral drugs to HIV patients showed that $6.67 \%$ of the respondents previously prescribed antiretroviral drugs to their patients. Whereas, 93.33\% had never encountered such an experience. [Figure 5]. Analysation of knowledge on the exact dosage of antiretroviral drugs demonstrated that 7 students were well aware of the exact dosage of antiretroviral drugs (5.83\%). Majority of the respondents had no knowledge on the exact dosage of antiretroviral drugs to be administered to HIV patients (94.17\%). [Figure 6]. 
Among 120 students, $63.33 \%$ of the respondents stated that they have knowledge on triple combination drugs and $36.67 \%$ of the respondents stated that they did not have knowledge on triple combination drugs. [Figure 7]. On top of that, the majority of the respondents stated that they believe drug resistance can cause failure of treatment (83.33\%).

Figure 10: Pie chart showing awareness of the adverse effects of antiretroviral therapy. 83.33\% of the respondents were aware of the adverse effects of antiretroviral therapy. $16.67 \%$ of the respondents had no awareness on the adverse effects of antiretroviral therapy

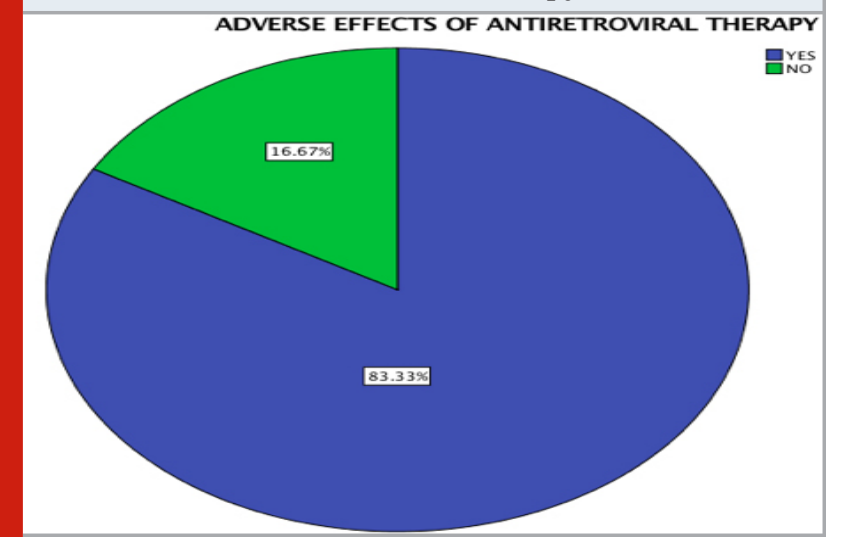

Figure 11: Pie chart showing awareness on development of oral lesions on prolonged use of antiretroviral therapy. 70\% of the respondents stated that oral lesions may develop on prolonged use of antiretroviral therapy (blue).

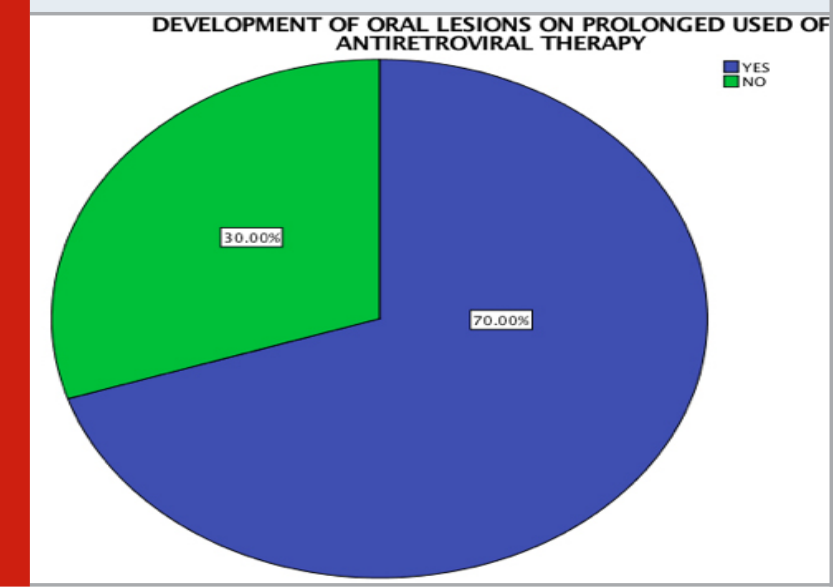

$16.67 \%$ of the respondents stated that drug resistance did not cause failure of treatment. [Figure 8]. Respondents that were aware of the importance of drug resistance testing for HIV patients were 70.83\% . While, 29.17\% of the respondents stated that drug resistance testing was not important. [Figure 9].

In addition to this, the majority of the respondents were aware of the adverse effects of antiretroviral therapy on the HIV patients (83.33\%). 16.67\% of the respondents had no awareness on the adverse effects of antiretroviral therapy. [Figure 10]. When enquiring about the awareness on development of oral lesions on prolonged use of antiretroviral therapy, most respondents agreed that antiretroviral therapy may cause development of oral lesions on prolonged usage (70\%). Only 30\% of the respondents stated that antiretroviral therapy would not cause oral lesions. [Figure 11]. Overall, 23.33\% of the respondents were aware that antiretroviral therapy caused delay of dental mineralization in paediatric patients. 76.67\% of the respondents were not aware of the negative effect of antiretroviral therapy on dental mineralization in paediatric patients. [Figure 12].

Figure 12: Pie chart showing awareness of antiretroviral therapy causing delay in chronology of dental mineralization in paediatric patients. $23.33 \%$ of the respondents believed that antiretroviral therapy caused delay of dental mineralization in paediatric patients. $76.67 \%$ of the respondents stated that antiretroviral therapy did not affect the dental mineralization of paediatric patients.

ANTIRETROVIRAL THERAPY CAUSE DELAY IN CHRONOLOGY OF DENTAL

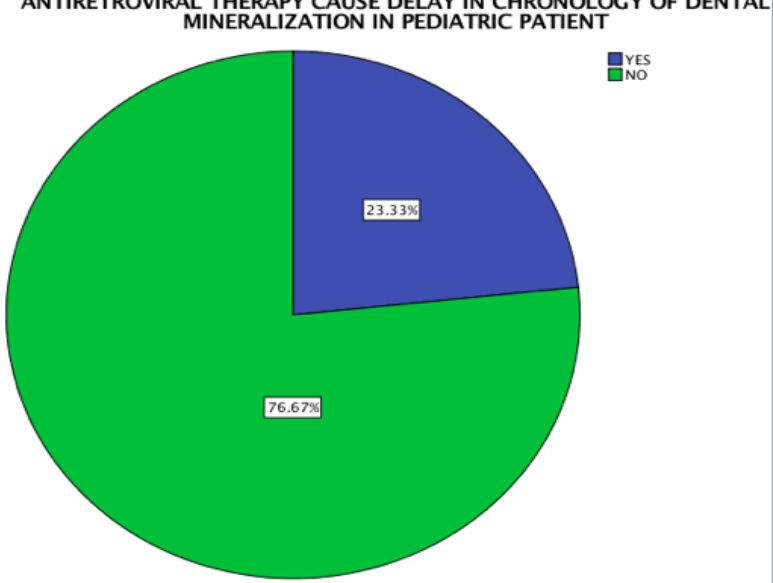

This cross sectional study was used to assess the awareness and knowledge of dentists toward the use of antiretroviral drug therapy in management of HIV. Most of the participants have good knowledge on antiretroviral drug therapy. The findings in the present study was coinciding with studies reported by Oberoi SS et al, Dhanya RS et al and Grover et al, but contradictory with study reported by Abou El Fadl et al (Grover et al., 2014; Oberoi, Sharma, et al., 2014; Dhanya et al., 2017; Abou El Fadl et al., 2019). Hence, it is important for every dentist to acquire their knowledge on antiretroviral therapy through their professional education (Singh et al., 2017), in order to deliver better treatment for their patients. This is because knowledge can affect the attitudes of dentists on treatment modalities for HIV patients (Oberoi, Sharma, et al., 2014).

In this present study, overall majority of the participants showed acceptable knowledge on the triple combination antiretroviral drugs, drug resistance, failure of antiretroviral therapy as well as on the adverse effects of drug reactions. Unfortunately, there were no previous literatures conducted on the knowledge and awareness of dentists of the antiretroviral drugs.

Basically, HIV is neither curable nor vaccine-preventable, but it can be prevented through health education 
(Sannathimmappa and Nambiar, 2019). Usually, HIV infected patients would be prescribed with antiretroviral drugs to control the progressions of disease. These antiretroviral drugs will help to increase the survival rate of HIV patients through highly active combination therapy (Raberahona et al., 2019). A study reported by Agu et al stated that antiretroviral therapy may cause adverse drug reactions (Agu, Oparah and Ochei, 2012). These statements justified the results in the present study, where the majority of the respondents believed that antiretroviral drugs may cause drug reactions. Antiretroviral drugs regimens are a combination of minimum three drugs with combined toxicities from the individual drugs. This may lead to adverse drug reactions, causing morbidity and mortality of the patients (Lazarou, Pomeranz and Corey, 1998; Agu, Oparah and Ochei, 2012). Therefore, it is important for dentists to know about the triple combination drugs and its adverse effects.

As the number of people with HIV/AIDS are increasing worldwide, more patients will seek medical and dental care (Singh et al., 2017). Thus, dentists must ensure that their patients strictly adhere to the antiretroviral therapy for effective treatment. However, prolonged use of antiretroviral drugs may lead to drug resistance, thereby limiting therapeutic purposes (ANONIMO et al., 2003; Focà et al., 2014). It also may lead to other complications in the oral cavity. Basically, short term use of HAART will improve the HIV patients oral health, but prolonged use of the drugs may have adverse effects on oral health. In this study, the majority of the respondents believe that HAART will cause oral lesions. This findings was supported by Nittayananta $\mathrm{W}$ et al, where he proves that long term use of HAART have adverse effects on oral health including presence of oral lesions (Nittayananta et al., 2010).

In addition to this, M Trigueiro stated that there was positive association between the use of antiretroviral therapy and a delay in the chronology of dental mineralization (Trigueiro et al., 2010). This statement justified the findings in this current study, where most of the participants were aware that antiretroviral therapy caused delay of dental mineralization in paediatric patients. This may be due to the association with HIV and also adverse effects of antiretroviral therapy. Hence, early intervention of dentists on treatment may help to prevent the adverse effects as well as providing better treatment modalities for the patients.

The limitation of the study was that results were based upon subjective assessment of each respondents of the questionnaire. A bigger sample size should be used in order to obtain a better outcome. On top of that, there were no previous literatures reported similar to the study. Thus, in future more studies should be conducted on the knowledge, practice and awareness of dentists of antiretroviral drugs in managing HIV patients.

\section{CONCLUSION}

Within the limits of study, the majority of students showed an acceptable level of knowledge and awareness on antiretroviral drugs in management of HIV patients. Association between response of the participants and knowledge on antiretroviral drugs was found to be statistically significant. However, there was a lack of knowledge on the dosage and prescription of the antiretroviral drugs. Hence, implementation of additional courses and programs are needed in order to improve their knowledge on antiretroviral drugs as well as its application in dental practices.

Authors Contribution: All authors have equal contribution in bringing out this research work.

\section{ACKNOWLEDGEMENTS}

Nil

\section{Conflict of Interest: Nil}

\section{REFERENCES}

Abou El Fadl, R. K. et al. (2019) 'Assessing the levels of HIV-related knowledge and attitudes toward HIVinfected patients among undergraduate dental students: a cross-sectional study', HIV/AIDS , 11, pp. 83-92.

Agu, K. A., Oparah, A. C. and Ochei, U. M. (2012) 'Knowledge and attitudes of HIV-infected patients on antiretroviral therapy regarding adverse drug reactions (ADRs) in selected hospitals in Nigeria', Perspectives in clinical research, 3(3), pp. 95-101.

Anbu, R. T. et al. (2019) 'Comparison of the Efficacy of Three Different Bone Regeneration Materials: An Animal Study', European journal of dentistry, 13(1), pp. 22-28.

ANONIMO et al. (2003) Adherence to Long-term Therapies: Evidence for Action. World Health Organization.

Ariga, P. et al. (2018) 'Determination of Correlation of Width of Maxillary Anterior Teeth using Extraoral and Intraoral Factors in Indian Population: A Systematic Review', World Journal of Dentistry, 9(1), pp. 68-75.

Ashok, V. and Ganapathy, D. (2019) 'A geometrical method to classify face forms', Journal of oral biology and craniofacial research, 9(3), pp. 232-235.

Blood', G. A. C. B. (arbeitskreis B. S. 'assessment of P. T. by, German Advisory Committee Blood (Arbeitskreis Blut) and Subgroup 'Assessment of Pathogens Transmissible by Blood' (2016) 'Human Immunodeficiency Virus (HIV)', Transfusion Medicine and Hemotherapy, pp. 203-222. doi: 10.1159/000445852.

Bonito, A. J. et al. (2001) Management of Dental Patients Who Are HIV Positive: Summary. Agency for Healthcare 
Research and Quality (US).

Broder, S. (2010) 'Twenty-five years of translational medicine in antiretroviral therapy: promises to keep', Science translational medicine, 2(39), p. 39ps33.

Campo, J. et al. (2007) 'Oral complication risks after invasive and non-invasive dental procedures in HIVpositive patients', Oral diseases. Wiley Online Library, 13(1), pp. 110-116.

Dhanya, R. S. et al. (2017) 'Knowledge, Attitude, and Practice towards HIV Patients among Dentists', Journal of International Society of Preventive \& Community Dentistry, 7(2), pp. 148-153.

Duraisamy, R. et al. (2019) 'Compatibility of Nonoriginal Abutments With Implants: Evaluation of Microgap at the Implant-Abutment Interface, With Original and Nonoriginal Abutments', Implant dentistry, 28(3), pp. 289-295.

Evaluation of Corrosive Behavior of Four Nickelchromium Alloys in Artificial Saliva by Cyclic Polarization Test:An in vitro Study' (2017) World Journal of Dentistry, 8(6), pp. 477-482.

Focà, E. et al. (2014) 'Clinical and immunological outcomes according to adherence to first-line HAART in a urban and rural cohort of HIV-infected patients in Burkina Faso, West Africa', BMC infectious diseases, 14(1), p. 153.

Ganapathy, D. M., Kannan, A. and Venugopalan, S. (2017) 'Effect of Coated Surfaces influencing Screw Loosening in Implants: A Systematic Review and Meta-analysis', World Journal of Dentistry, 8(6), pp. 496-502.

Grover, N. et al. (2014) 'Attitude and knowledge of dental students of National Capital Region regarding HIV and AIDS', Journal of oral and maxillofacial pathology: JOMFP, 18(1), pp. 9-13.

Gupta, P., Ariga, P. and Deogade, S. C. (2018) 'Effect of Monopoly-coating Agent on the Surface Roughness of a Tissue Conditioner Subjected to Cleansing and Disinfection: A Contact Profilometric Study', Contemporary clinical dentistry, 9(Suppl 1), pp. S122S126.

Jaffar, S. et al. (2004) 'The natural history of HIV-1 and HIV-2 infections in adults in Africa: a literature review', Bulletin of the World Health Organization. World Health Organization, 82, pp. 462-469.

Jain, A. R. (2017a) 'Clinical and Functional Outcomes of Implant Prostheses in Fibula Free Flaps', World Journal of Dentistry, 8(3), pp. 171-176.

Jain, A. R. (2017b) 'Prevalence of Partial Edentulousness and Treatment needs in Rural Population of South India', World Journal of Dentistry, 8(3), pp. 213-217.
Keser, G., Göcüncü, N. and Pekiner, F. N. (2019) 'Assessment of knowledge level about acquired immune deficiency syndrome and patient approaches of dental students', Nigerian journal of clinical practice, 22(9), pp. 1259-1265.

Lazarou, J., Pomeranz, B. H. and Corey, P. N. (1998) 'Incidence of adverse drug reactions in hospitalized patients: a meta-analysis of prospective studies', JAMA: the journal of the American Medical Association, 279(15), pp. 1200-1205.

Levy, J. A. (2007) 'HIV and the Pathogenesis of AIDS, Third Edition'. doi: 10.1128/9781555815653.

Magalhães, V. C. S. de, Oliveira, D. L. de and Prado, F. 0. (2015) 'Knowledge, risk perception and attitudes of Dentistry students with regard to HIV/AIDS', RGO - Revista Gaúcha de Odontologia. Faculdade São Leopoldo Mandic, 63(3), pp. 291-300.

M. Trigueiro S. V. Tedeschi-Oliveira R. F. H. Melani K. L. Ortega. (2010) 'An assessment of adverse effects of antiretroviral therapy on the development of HIV positive children by observation of dental mineralization chronology', Journal of Oral Pathology and Medicine, 39 : 35-40

Nittayananta W, Talungchit S, Jaruratanasirikul S, et al. (2010) 'Effects of long-term use of HAART on oral health status of HIV-infected subjects', J Oral Pathol Med, 39(5):397-406.

Oberoi, S. S., Sharma, N., et al. (2014) 'Knowledge and Attitude of Faculty Members Working in Dental Institutions towards the Dental Treatment of Patients with HIV/AIDS', International scholarly research notices, 2014, p. 429692.

Oberoi, S. S., Marya, C. M., et al. (2014) 'Knowledge and attitude of Indian clinical dental students towards the dental treatment of patients with human immunodeficiency virus (HIV)/acquired immunedeficiency syndrome (AIDS)', International dental journal, 64(6), pp. 324-332.

Raberahona, M. et al. (2019) 'Knowledge, attitudes, perception and practices regarding antiretroviral therapy among HIV-infected adults in Antananarivo, Madagascar: a cross-sectional survey', BMC health services research, 19(1), p. 341.

Ranganathan, H., Ganapathy, D. M. and Jain, A. R. (2017) 'Cervical and Incisal Marginal Discrepancy in Ceramic Laminate Veneering Materials: A SEM Analysis', Contemporary clinical dentistry, 8(2), pp. 272-278.

Sannathimmappa, M. B. and Nambiar, V. (2019) 'HIV/ AIDS and Its Prevention: A Cross-sectional Study to Evaluate Knowledge, Awareness, and Attitude among 
Medical Students', Health Sciences, 8(8), pp. 110-116. Singh, V. P. et al. (2017) 'Knowledge and Attitude of Dental Students towards HIV/AIDS Patients in Melaka, Malaysia', The Malaysian journal of medical sciences: MJMS, 24(3), pp. 73-82.

Varghese, S. S., Ramesh, A. and Veeraiyan, D. N. (2019) 'Blended Module-Based Teaching in Biostatistics and Research Methodology: A Retrospective Study with Postgraduate Dental Students', Journal of dental education, 83(4), pp. 445-450.

Website (no date). Available at: AEGIS Communications, Scarlett BMI, D. Dental Treatment Issues for Patients With HIV/AIDS. AEGIS Dental Network [Internet]. 2009 [cited 2020 Jun 30];5(6). Available from: https://www. aegisdentalnetwork.com/ida/2009/06/dental-treatmentissues-for-patients-with-hiv-aids (Accessed: 30 June 2020). 